all times if so required. During the year, the student-doctor should certainly continue with his reading. But I would suggest that in the main this should consist of the current journals and reading about the conditions he is involved in treating, and that this is not a period for any formal, systematised reading. Similarly he should be encouraged to attend case-conferences and discussions taking place in the hospital or department in which he is working, and it is valuable for him to present patients at these conferences from time to time. But I would suggest that during this period of training he should not have time off to attend courses or any formal teaching sessions.

To conclude, I would summarise my remarks by saying that in his pre-qualification years a student is learning medicine, and in his preregistration year is learning to become a doctor. This is clearly a great oversimplification but contains, I suggest, the essential truth about a complex educational process designed to produce at its end a doctor capable of utilising his talents to their utmost in his own chosen portion of the wide, rich fields of Medicine.

\title{
SPECIAL VOCATIONAL TRAINING FOR THE SPECIALTIES
}

\author{
A. Paton, M.D., M.R.C.P. \\ Physician, Dudley Road Hospital, Birmingham.
}

I MUST begin by saying that I do not feel altogether happy about the title of this talk. Firstly, "vocational" seems to me altogether too narrow a definition for training a specialist, if by this is meant merely learning a trade. Secondly, while I can speak with some assurance about the specialty of medicine, I am not sure that what I have to say necessarily applies to all specialties. And thirdly, I will have to exclude any consideration of the important, and to my mind, largely unexplored role of hospitals in training for the specialty of general practice.

I would like to divide this talk into three parts-the man, the job and the means. First, the man. I hope he will be well trained in the basic sciences, with perhaps a B.Sc. or an honours degree, and at the same time keenly interested in people as human beings. He will of course be motivated by an intense desire to become a hospital consultant, and will not mind putting up with some adversity to achieve his goal. I do not think it right that the path should be made too easy for him in material terms as is currently suggested, but his youthful enthusiasm, energy and potentiality should be fully recognised and encouraged, as is more commonly the case in the United States than in this country. He will I hope have learnt to take nothing on trust, but to observe and question with a due sense of humility. He should recognise that specialisation inevitably means dedication to a narrow and time-consuming discipline, and should try to offset this by $a_{\sigma}$ practical interest in and awareness of other aspects of life. Having myself married soon $\frac{0}{0} \vec{\circ}$ after qualifying, I am naturally glad to be able to point out that it is no longer necessary for the aspiring consultant to remain celibate, but I would suggest that he tactfully point out to his wife that his specialty comes first and the family second.

And now the job. Having finished his preregistration appointments the young man who wishes to specialise immediately comes up against a hurdle - the difficulty of obtaining a senior house officer post. One of the best house physicians I have had, who was unfortunately bent on a career in surgery, took nearly three months to get such a post, and I believe this experience is not unusual in all specialties. Having achieved this step however he is not likely to find it so difficult to get a registrar appointment and this will almost certainly be in a regional hospital. I am sure this is the place from which higher examinations should be taken, and the sooner they are taken the better. I know the criticisms: inadequate teaching, registrars used as "pairs of hands," no time for thought or study. Sir George Pickering (1962) was worried that the young man in the regional hospital might be a menace because of the lack of intellectual stimulus and educational minds. I think he can be reassured. The tremendous upsurge in postgraduate education, sparked off by Pickering himself, the increasing 
practice of inspection of hospitals by the Royal Colleges, and closer integration with teaching hospitals will I hope allay his and others' fears.

We certainly recognise that our registrars are there to pass their specialist examinations and that our help-and their success-can do nothing but good in attracting the right type of candidate for the job. There are complaints about poor facilities for study and inadequate time off for study leave, but my experience is that regional hospitals are liberal in these respects. Our registrars can obtain a month's study leave for each year of service, and the principle of a half-day or even a full day off a week to attend courses is increasingly accepted. Registrars in regional hospitals have the added advantage of being the only ones taking ex. aminations and therefore do not have to com. pete with the needs of undergraduates.

What should the young man do once he has got his higher degree? If he is still young, I think this might well be a good time to pause and step back into the world again. Before the war, this would have meant a voyage round the world as a ship's doctor; after the war, a period of National Service. Fortunately, there are still many parts of the world where the young British doctor is welcome, and there he can broaden his mind. But there is that well known bogey, the consultant ladder. I remember the horror with which some of my colleagues greeted the announcement of one of our bright young registrars that he was off to Bahrain for two years. "How will you ever get back onto the ladder?" they asked.

Those who stay at home will rightly turn their eyes towards the teaching hospital for experience in academic medicine, teaching and research. I firmly believe that all young men who intend to specialise, whatever the specialty, should undertake research, not just so that they can write papers but to keep alive that spirit of enquiry and self-criticism which is the prerogative of youth, but which tends to atrophy with advancing age and establishment. I would like to see regional hospitals taking a greater part in research, but it is not easy to persuade young men of its importance when their minds are set on higher examinations. Once passed however there is no reason why they should not do research in a regional hospital and the Birmingham Regional Board has already established a number of Sheldon Fellowships for this purpose.

The final step for the potential consultant is of course a senior registrar appointment. This will normally be in a teaching hospital, with a few posts in which there is rotation with a regional hospital. In the latter case he must spend his final years in the teaching hospital, so as to be in the best position for obtaining a consultant appointment. He will now have increasing responsibility, should be writing an M.D. thesis and should be teaching housemen and registrars as well as students. He should be encouraged to travel abroad, and not necessarily to America, and the year "off service" which is currently given to Senior Surgical Registrars in this medical school is a scheme which could well be more widely adopted.

Lastly, the means. This conference is called "The Postgraduate Medical Centre", but in training for the specialties, I cannot envisage anything so narrow as a centre. I would prefer to see much wider use of regional hospitals and their closer integration with the teaching hospitals, rather than separate postgraduate institutions. The techniques of teaching are too well-known to require elaboration: ward rounds, more formal staff rounds, seminars, clinicopathological conferences and journal clubs (noo one seems to teach the art of reviewing the literature), conducted as far as possible by the registrars but always fully supported by con sultant staff. I like the idea of the "peripatetice professor" (poor man) who comes to discuss one or two well-presented patients-and how bad the young registrar is at case presentation when he first starts! Registrars should be encouraged to keep case summaries of patients they have attended and to start filing systems of the literature. There is much criticism these days of examinations, but I firmly believe that teaching examination techniques is much more than just a utilitarian exercise. Research, as I have said, I regard as mandatory, and an M.D. by thesis as complementary to the higher degree. I hope it will never be necessary to remind teachers or taught of their first responsibility to the patient. Professor Donald (1959) was rightly irritated by the question: "Do you actually treat patients?"

Neither must the teacher lose sight of his student. In many regions there are already numbers of postgraduate clinical tutors, and surely one of their most important functions must be to give advice and help to young men intending to specialise. The medical student is fortunate in having many advisers; once qualified he is often left to make his own way, and there is frequently a need for someone to whom to turn. The difficulty is to be honest when the truth may be unpalatable. One should 
not forget either that the teacher needs time for thought and study, though I am opposed to the full-time clinical postgraduate teacher. To my mind there is nothing like a busy clinical practice to stimulate the teacher, especially if he is, as he should be, a bit of a showman. But perhaps one day we too will have our sabbatical years. Finally, the delight of postgraduate education is surely that there is no distinction between teacher and taught. Each learns from the other, and for both the words of Solon are appropriate: "Older now and growing older every day, there is not a day passes without my learning more".

\section{REFERENCES}

Donald, K. W. (1959): Research and Clinical Medicine, Lancet, ii, 801.

Pickering, G. (1962): Postgraduate Medical Education: the Present Opportunity and the Immediate Need, Brit. med. J., i, 421.

\section{DISCUSSION}

Professor Hubble considered that the work of the preregistration year was too hard to allow much time for study: formal training was necessary to remedy this but how many hours should be devoted to it and how many to actual work? This would create the need for more junior staff.

Sir GeORGe PICKERING disagreed with the speaker in not aiming at a uniform product at the end of the pre-registration year. Sir Humphrey Rolleston once said that one's housejob was one's most important job, and the most important thing about it was for whom one did it. The houseman must know how to take a good history, and how to examine the whole body: elementary observations were essential. If these things had not been learnt by the end of the preregistration year they never would be. The job must be the kind where this was learnt, and done at a place where the chief minded and general practitioners were not looking on.

Dr. A. A. G. LewIS (British Postgraduate Medical Federation) thought that casualty jobs should not be pre-registration posts. In hospitals all over the country, inexperienced young house officers were being called on to take far more responsibility than they should do in casualty departments-this was as bad for them as it was for the patients, but presumably only a major legal action would stop this.

Mr. D. C. Bowie (Postgraduate Medical Federation) disagreed. He considered that there was an enormous amount of experience to be gained by emergency work in Casualty Departments provided there was adequate supervision. Certain Royal Colleges are running a series of meetings for pre-registration house officers in London-surely this effort should be made in the hospitals in which they hold their appointments. DR. W. CALVERT (Stockport) said that pre-registration jobs were a device for staffing hospitals - when had they been considered anything else? If these men were not to be regarded as pairs of hands the whole staffing system would need revision.

DR. R. E. SMITH (Coventry) said that qualification was a dividing line-the poorer students went out to the periphery, and after their pre-registration year some were not worthy of being signed up.

Mr. M. R. Williams (Canterbury) agreed that the function of the pre-registration year was to learn to practice medicine. There should be no pre-registration jobs in teaching hospitals - there were too many senior men around to prevent the young man taking decisions and making up his own mind. In provincial hospitals he meets a smaller number of chiefs and may eat with them and meet them frequently.

PROFESSOR MCGIRR (Glasgow) said that certain jobs were not suitable. Most medical schools should be making a selection of jobs suitable for further education. It was important for the young man to work for someone who had his interests at heart and who could delegate reasonable responsibility.

PROFESSOR LE QUESNE agreed that the suitability of jobs as pre-registration posts was a very important question. He could not agree that teaching hospital jobs were not suitable. Teaching hospitals ought to provide the most stimulating environment in the jobs in that atmosphere. Provided that help is always and readily available he did not think it was wrong for pre-registration men to work in Casualty Depart-? ments.

DR. J. Wedgwood (Bury St. Edmunds) asked about the role of Commonwealth postgraduates.

PROFESSOR HUBbLe asked if the G.M.C. should compile a Registry of Specialists.

SIR GEORGE PICKerING asked what was the role of the Royal Colleges?

DR. JOHN ELLIS (ASME) asked what was the role of the Universities in postgraduate medical education? He was very interested in the one year off servicewas it with pay?

Professor Gray (Liverpool) Was it for research or travel?

DR. WhitTakeR (Warwick) asked how much time this was going to take for the clinical tutors. Some were already spending up to 2 or 3 sessions a week on this work. Should their contracts be altered? $£ 100$ was obviously not an adequate reward-allowance must be made for the time this took. It was particularly difficult for some who were very fully occupied -for instance, maximum part-time surgeons.

Professor Hubble asked if this were a Ministry of Health responsibility.

DR. WhITTAKER replied that all these people were under contract with the Board though technically the tutor's job was a University one.

DR. K. O. RAwLINGS (Farnborough) said that as the number of registrar posts at teaching hospitals was limited it was very difficult for a registrar at a regional hospital to get back on the "ladder", the only way he could expect to reach consultant status eventually. If he went abroad to say Bahrain for a year, what were his chances of getting back on the 
"ladder"? Regional hospitals provide tremendous clinical experience, and registrars as well as senior registrars from teaching hospitals should have the opportunity of working in them without prejudicing their future.

Mr. G. J. Hadfield (Aylesbury) said that the term "Teaching Hospital" should cover all hospitals where people were taught. The formation of an Association for the Study of Medical Education showed that this idea had spread and should be recognised as having done so. Research could also be done at the periphery: it was important for everyone, as part of our education. Many Boards give prizes for research by registrars. Regional hospital surgeons should encourage this.

PROFESSOR MCGIRR asked how much formal instruction should be given to registrars. How much is done to notate them through different firms to enlarge their experience? Are we going to rotate them through narrow specialties or just give them general training? He thought that it was written in the conditions of service that everyone should have a year off. Do we use the membership examination to set standards of training or achievement? The Scottish Membership may not be regarded as the equivalent of the London one for this, which is unsatisfactory. It should be the responsibility of universities within their own sphere to provide facilities for research for registrars and senior registrars.

DR. PAulley thought there was some danger in elevating the status or financial rewards of tutors. This might estrange their colleagues. It should be the job of all consultants to teach, and their cooperation must not be lost.

DR. D. H. ClaRK (Cambridge) remarked that other groups besides physicians in the N.H.S. have to be trained. Dr. Paulley had not mentioned psychiatrists. They had their problems for there was no real undergraduate training and other disciplines had to be mastered. This applied to other specialties-e.g., anaesthetics.

Mr. P. Gilroy Bevan (Birmingham) answered the question of what the Colleges were doing from the surgical point of view. The pilot scheme for surgical training initiated nearly three years ago by the Royal College of Surgeons of England deserved tribute. Recently surgical tutors had been asked for preliminary ideas for putting the scheme on a permanent basis. More tutors would be needed-should every hospital group have one? He was against full time tutorial appointments, but the work took a considerable amount of time. Registrars had to fit their studies in amidst full time clinical duties. Now that postgraduate training was gaining official recognition, the inescapable conclusion was that sessions would have to be allowed for it, and this would mean some increase in establishment for both teachers and the taught.

DR. I. J. Voss (Kettering) said that the clinical tutor should interest himself in the amount of teaching residents were getting. There were great variations in the amounts given by different chiefs. He challenged the idea that where a job was done was more important than what the job was. The old prejudice against regional hospital registrar jobs was going. The registrar must have the broad experience that only a regional hospital can give.

DR. PAton said that teaching hospitals must decide what they were going to do. There was no distinction now-we must all teach. The universities might create units for postgraduate education in regional hospitals with or without our help. A register of specialists was necessary. "One year off service" for senior medical registrars in the Birmingham region was intended for research or travel, or for work in a specialized centre; it was paid. He found that heo had to spend $25 \%$ of his time on postgraduate act- $?$ ivities and the work of the centre was increasing this. Of course, no one worked in isolation. As to the fears of young men losing their places on the ladder, he thought that they might be allowed to study something other than medicine. We must train general physicians and surgeons "with an interest"research was essential for all. The problem of the proliferation of higher qualifications must be tackled.

\title{
SPECIAL VOCATIONAL TRAINING FOR GENERAL PRACTICE
}

\author{
J. P. Horder, M.A., B.M., B.Ch., M.R.C.P. \\ Chairman, Committee on Vocational Training: College of General Practitioners
}

\section{The Present}

IN this country we give the shortest training to our largest group of doctors, the group which has the largest power to decide whether or not patients will get what medicine can offer them. Other countries give as little or less training to their general practitioners but few other countries still give them so much power and make it so difficult for patients to bye-pass them. Here is a situation crying for reform. Let us look more closely at the present position.
No one believes any longer that undergraduate medical education can or should turn out a safe general practitioner. Its purpose is to provide a basic education in medicine. Special vocational training must be provided after qualification. General practitioners need special vocational training just as surgeons do. The provision of it for them is long overdue and I believe that this failure has a fundamental bearing on the dangerous situation which we have recently been witnessing in the general 